\title{
Terapia com ondas de choque no tratamento da fratura de terceira falange em um equino: relato de caso
}

Luis Fagner da Silva Machado $0^{[a]}$, Mariana Cocco ${ }^{[b]}$, Flávia do Prado Augusto Amaro[b], Luiza Costa Barcellos ${ }^{[b]}$, Bruna Lampe Zielinski $^{\left[{ }^{b}\right]}$, Lidia Dornellas de Faria ${ }^{[c]}$, Peterson Triches Dornbusch ${ }^{[b]}$

\footnotetext{
[a] Universidade Regional de Blumenau (FURB), Blumenau, SC, Brasil

[b] Universidade Federal do Paraná (UFPR), Curitiba, PR, Brasil

[c] Médica veterinária, Brasília, DF, Brasil
}

*Autor correspondente

e-mail: mariana.cocco@hotmail.com

\section{Resumo}

A fratura de terceira falange em equinos é de ocorrência frequente, mas apresenta um prognóstico reservado dependendo do tratamento empregado, sendo que este tem por objetivo estabilizar a fratura e impedir o movimento da falange dentro do estojo córneo, podendo ser conservativo, aliando repouso e ferraduras ortopédicas, ou cirúrgico, utilizando parafusos compressivos. 0 tempo de recuperação é longo, podendo variar de 6 a 12 meses. 0 tratamento com ondas de choque (ShockWave) consiste na aplicação de ondas que atravessam os tecidos e fluídos produzindo uma deformação mecânica, que provoca alterações bioquímicas e acarreta na proliferação celular. 0 presente trabalho tem por objetivo relatar o tratamento com ondas de choque em uma fratura de terceira falange. Um equino, macho, raça Crioula, 4 anos, foi atendido com histórico de trauma na face solear do casco do membro torácico esquerdo. Ao exame clínico, apresentava claudicação grau IV, aumento de temperatura no casco, pulso da artéria digital intenso, posição antálgica de alívio flexionando as articulações distais do boleto e falanges, com apoio em pinça sem carga e sensibilidade à pinça tenaz de casco. 0 diagnóstico de fratura de terceira falange longitudinal medial articular foi confirmado por meio de avaliação radiográfica. 0 tratamento realizado constituiu de ferradura ortopédica, anti-inflamatório não esteroidal (AINES) firocoxibe $(0,12 \mathrm{mg} / \mathrm{kg}$, SID, IV) durante 20 dias, ácido tiludrônico (500 mg, dose única, IV), quatro doses a cada 7 dias de pentosano polissulfato de sódio $(2,5 \mathrm{mg} / \mathrm{kg}$, IM), infiltração da articulação interfalangeana distal com hialuronato de sódio $(20 \mathrm{mg})$ e cinco sessões de ondas de choque com intervalo de 30 dias entre elas. A ferradura ortopédica consistia de quatro guarda-cascos laterais soldados no exterior dos ramos da ferradura, próximos à junção dos quartos e talões, associada a uma barra no meio da sola, e esta preenchida com massa epóxi. Após a quarta sessão de ondas de choque 
(150 dias), foi confirmada a consolidação da fratura por meio do exame radiográfico, mas mesmo assim foi realizada mais uma sessão e o paciente retornou às suas atividades. Fraturas de terceira falange com envolvimento articular, como a observada no caso, são mais comuns e com prognósticos mais desfavoráveis, pois podem levar a um processo de osteoartrite da articulação interfalangeana distal. Estas fraturas geralmente são tratadas de forma conservativa, baseando-se em repouso e uso de ferradura ortopédica, o que torna a recuperação mais onerosa e demorada. Em contrapartida, o tratamento com ondas de choque é uma tecnologia não invasiva e sem complicações, utilizada como aliada à cirurgia e ao tratamento conservativo, podendo encurtar o período de recuperação. Este tratamento promove neovascularização, ativa os fatores osteogênicos locais e estimula fatores de crescimento como VEGF (fator de crescimento do endotélio vascular) sem lesar os tecidos moles. Além do desencadeamento do processo anti-inflamatório e cicatrizante no tecido, ela também causa analgesia desde a primeira sessão. Neste caso, além do tratamento com ondas de choque, também foi utilizado a ferradura ortopédica e a infiltração articular com hialuronato de sódio, tratamentos estes que são amplamente utilizados e mostram altos índices de sucesso, colaborando também com o êxito final obtido. Conclui-se que o uso das ondas de choque aparentemente auxiliou na diminuição do tempo de convalescença, entretanto, mais estudos clínicos são necessários para confirmar sua eficácia no tratamento de fraturas em equinos.

Palavras-chave: Fratura. Terceira falange. Ondas de choque. 